\title{
PARAMETERS AFFECTING QUALITATIVE AND EFFICIENT ELECTRODEPOSITION OF METALS IN AN ELECTROLYTIC CELL: A REVIEW
}

\author{
${ }^{* 1}$ Arowolo, M. O., ${ }^{1}$ Adekunle, A. A. and ${ }^{2}$ Odejobi, Olusegun A. \\ ${ }^{1}$ Department of Mechatronics Engineering, Federal University Oye-Ekiti Ekiti State, Nigeria. \\ ${ }^{2}$ Prototype Engineering Development Institute, Ilesa, Nigeria \\ *Corresponding Author's Email: arowolo.oluwole@ fuoye.edu.ng
}

\begin{abstract}
Electroplating has been a useful practice in the laboratory and industry for a long time. Its usefulness is more profound in oil industries for corrosion prevention and control, automobile industry, jewelries and decoration. Today, the scope of electroplating has expanded considerably with many players exploring its advantages and optimizing its parameters for enhanced productivity. The paper presented a review of electroplating with the aim of making concise information available on its process parameters and its process optimization. The review was compiled from several major work which pertained to parameters affecting qualitative and efficient electrodeposition of metals in an electrolytic cell. Results gathered included actual effect of identified parameters and interplay of parameter on quality of electrodeposition and microstructure of deposited metal. Important recommendations were made to further enhance the practice of electrodeposition.
\end{abstract}

Keywords: Electroplating, Efficient Electrodeposition, Electrodes, Electrolyte, Operating Parameters

\section{INTRODUCTION}

Electrodeposition is a technological process for the production of a material using an applied potential difference or current flowing in an electrolytic cell containing metal ions to form metal, metal alloys or composites as a coating for another metal (Zangari, 2018). The product of electrodeposition is a dense, uniform and an adherent coating usually of metal on another conducting surface (ASTMB374-06, 2019). This process is usually carried out either to achieve properties not originally exhibited by a material or to enhance such properties such as wear resistance, corrosion protection, lubricity, conductivity, aesthetics, etc. Electrodeposition is an important industrial process; this technology has a long history dated back to eighteenth century. In 1801, electroplating was reported and experiments for depositing dendritic metallic lead and copper onto a surface using Volta piles (Garcia \& Burleigh, 2013). Also, an Italian scientist, Luigi Brugnatelli, in 1805 published on the use of Volta piles to deposit a layer of gold onto another metallic surface (Thomson, 1813).

Electrodeposition has equally found an important use in the area of microfabrication and nanotechnology research (Andre \& Maximiliano, 2006). It is therefore of important proportion to be able to obtain a good quality metal deposition and through an efficient process. Many authors have researched the field of electroplating with impressive findings and report. The special interest in the field is connected with the multifarious applications of electroplating in research and industry. Electroplating has many advantages in the industry and these constitute a major drive for research. The electrodeposition of metallic, ceramic or polymeric particles embedded in a metal matrix has become a mature technology which continues to evolve and diversify (Walsh et al.,2020). The present study provides a concise review of electrodeposition parameters and their interplay during the process.

\section{BACKGROUND}

Electrodeposition or electroplating as electrochemical process obeys electrochemistry fundamental laws, Michael Faraday formulated two laws of electrolysis indicating the balance of mass and charge in electrochemical reactions (Zangari, 2018). Lou and Huang held that whenever a current is passed through an electrolyte, a chemical reaction takes place at the electrodes (Lou \& Huang, 2006). Metal deposition takes place according to Faraday's laws of electrolysis (Walsh et al., 2020). The reaction is as depicted by the following equations;

Cathode reaction (reduction): $M^{n+}+n e^{-}$

$$
\begin{aligned}
& \rightarrow \text { MAnode reaction (oxidation): } M \\
& \rightarrow M^{n+}+n e^{-}
\end{aligned}
$$

Figure 1 shows the schematics of an electrolytic cell for deposition of a metal from a solution of the metal salt. 


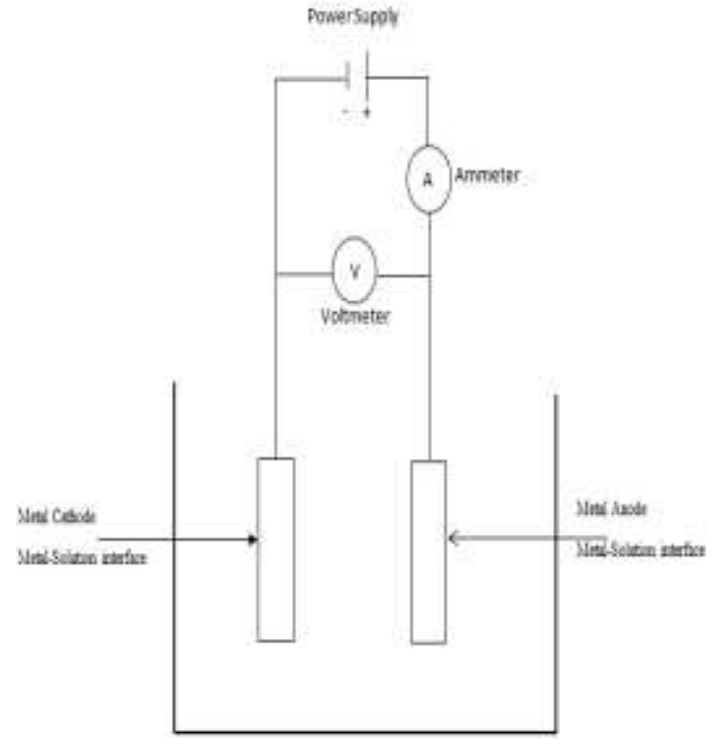

Fig. 1: Schematics of an electrolytic cell for plating metal "M" from a solution of the metal salt "MA"

Faraday's first law is summarized by the equation;

$M=K Q=K I t$

where $\mathrm{M}$ is mass deposited at cathode in grams $(\mathrm{g}), \mathrm{K}$ is the Proportionality constant - electrochemical equivalent (mg/As), I is Current in amperes (A) and $t$ is Time for which current flows in seconds (s). Given a negligible secondary reaction at the electrodes and a constant current flow, the above equation will accurately estimate mass deposited (Andre \& Maximiliano, 2006). Quality electrodeposition depends on right combination of process or operational parameters.Notable emphasis has been on investigation of process parameters as it affects electrodeposition of metals from an electroplating bath (Tuaweri et al., 2013; Bograchev \& Davydov, 2019). However, for a transient current condition where the instantaneous current is not constant, the weight deposited and the thickness of deposition can be estimated by relating equations (2) to (5) below to derive equation (6)

$m=\frac{Q}{n F}$

$Q=\int I d t$

$K=\frac{M_{w}}{n F}$

$w=\frac{M_{w}}{n F} \int I d t$

$\delta=\frac{W}{\rho A}=\frac{M_{w}}{n F \rho A} \int I d t$

and by solving the resulting equation (6) (Han, 2012). Where $\rho$ is the density of the metal $\left(\mathrm{g} / \mathrm{cm}^{3}\right), \mathrm{N}$ is the number of valence electron in the metal being deposited, $\mathrm{A}$ is the area of deposition $\left(\mathrm{cm}^{2}\right), \mathrm{F}$ is the Faraday constant which is $9.65 \times 10^{4}(\mathrm{C} / \mathrm{mol}), \delta$ is the deposition thickness in $\mathrm{cm}, \mathrm{M}_{\mathrm{w}}$ is the atomic weight of the metal being deposited and $\mathrm{W}$ is the weight of the deposit. The accuracy or otherwise of these equations is impacted by other factors that generally impact electrodeposition such process factors were listed to include bath concentration, agitation, time, current density, $\mathrm{pH}$ and electrolyte temperature (Kumar et al., 2015).

These and others are the factors that inter-relate to influence the quality of deposit (Sadiku-Agboola et al., 2011). Also of importance is the influence of process parameters on electrodes used in electroplating (Begum et al.,2013). Of course, this essentially affects the anode. A consideration of control and optimization of identified process parameters is significant for successful electroplating (Prasad et al., 2000; Noh, et al.,2011; Khedekar et al.,2016).

The microstructure of electrodeposit is often a good pointer to quality electrodeposition (Trzaska \& Trzaska, 2008). In general, a smooth morphology, small grain size or refined grains, and fine texture are desirable (Rashidi \& Amadeh, 2010; Esmar, et al., 2020). Such structures are generally observable using electron microscopes.

\section{ELECTRODEPOSITION PARAMETERS}

A number of parameters interplay during electrodeposition and may be broadly categorized into chemical, electrical and physical parameters. These parameters are briefly considered in the following paragraphs.

\section{CHEMICAL PARAMETERS}

The electrolyte is a major component in electrodeposition and its composition determines the integrity of the plated workpiece and the process. Chemical parameters revolve centrally around the electrolyte or bath and pertains to concentration of the electrolyte, $\mathrm{pH}$, and additives among others.

\section{Concentration of Electrolyte}

Prasad et al., (2000) found that although bath with $0.20 \mathrm{M}$ cobalt sulphate yielded acceptable deposition, increasing the concentration to $0.40 \mathrm{M}$ resulted in enhanced current efficiency during deposition of boron-containing amorphous metallic layer of cobalt-molybdenum alloy. High bath concentration will ordinarily increase the deposition rate of the plating process (Kumar et al., 2015). To obtain a Cu-coating on Magnesium Lithium( $\mathrm{Mg}-\mathrm{Li})$ alloy substrate, Yin et al. found a $50 \mathrm{~g} / \mathrm{L}$ concentration of the main salt to be optimum for the electrolyte (Yinet al., 2013). The surface morphology and composition of the electrodeposit in Tin-Bismuth (Sn-Bi) deposition is influenced by concentration of Tin ( $\mathrm{Sn}$ ) metal salt in the electrolyte. Sn content in the deposits increased with an increase of Sn metal salt content in the bath (Heonget al., 2012).

It was reported by (Sadiku-Agboola et al, 2011) that in bright nickel plating, the concentration of nickel salt has an effect on the weight of nickel deposited on the cathode. Agasti et al., (2014) while studying optimization of zinc salt concentration in 
co-electrodeposited Copper Zinc Tin Sulfide $\left(\mathrm{Cu}_{2} \mathrm{ZnSnS}_{4}\right)$ also reported that $\mathrm{Zn}$ content (atomic \%) becomes very high for the films with $\mathrm{ZnSO}_{4}$ bath concentration $0.06 \mathrm{M}$ and more compared with concentration of $0.03 \mathrm{M}$. During composite electroplating of Zinc Nano- Titanium dioxide, the weight percentage of Titanium dioxide $\left(\mathrm{TiO}_{2}\right)$ particles embedded in the deposited composite were influenced by the concentration of $\mathrm{TiO}_{2}$ in the electroplating bath among other factors (Mokabber et al., 2013). The influence of electrolyte concentration on electrodeposition was underscored by $\mathrm{Yu}$, et al in their work, they showed that the effect of concentration may be complex depending on other interacting conditions by concluding that Iron (Fe) content of the deposited Nickel Iron Tungsten $(\mathrm{NiFeW})$ alloy increases from 4.37 to $8.1 \%$ with the increasing of Iron (II) chloride $\left(\mathrm{FeCl}_{2}\right)$ concentration in the range of $1.5-3.6 \mathrm{gl}^{-1}$ and it tends to increase very slowly with higher $\mathrm{FeCl} 2$ (Yuet al., 2017). Analysis on the influential factors of Copper (II) $\mathrm{Cu}^{2+}$ electrodeposition revealed that concentration of $\mathrm{Cu}^{2+}$ in the electrolyte influenced amount of Copper deposited at cathode (Sui et al., 2017). Metal salt concentration is a crucial and influential factor in electrodeposition as myriads of work done by researchers pointed in this direction.

\section{Use of Additives}

Presence of additive tends to increase current efficiency and soundness of electrodeposits, for example Presence of an additive $17.0 \mathrm{~g} / \mathrm{L} \quad(\mathrm{NH} 4)_{2} \mathrm{SO} 4$ to the electrolyte in the electrodeposition of Cobalt Boron Molybdenum (CoMoB) amorphous alloys increased the soundness of the deposits (Prasad et al, 2000). Tang reported an improvement in ultimate tensile strength as well as ductility of Nickel plated from electrolyte with presence of additive compared with bulk Nickel (Tang et al., 2010). Certain surface properties such as hardness may be increased by additives (Trzaska \& Trzaska, 2008). The use of appropriate additives and in the right concentration can be used to increase growth of deposits during electrodeposition (Si et al., 2016). Some additives are used with the primary purpose of improving the physical appearance of the plated metal as depicted by the electrodeposition of a bright cyclic multilayer Zinc cobalt ( $\mathrm{Zn}$-Co) from electrolyte having a stable bath with Thiamine Hydrochloride (THC) as additive (Bhat \& Hegde, 2012).

\section{Electrolyte pH}

According to (Prasad et al., 2000), the best electrodeposition results are obtainable in the $\mathrm{pH}$ values ranging from 5.0 to 6.0 . Increase in $\mathrm{pH}$ results in increase in cathode current efficiency (Tuaweri et al., 2013). Additives are often added to the electrolyte but the $\mathrm{pH}$ of the bath determines adsorption of such additives (Kumar et al., 2015). Furthermore, Kumar \& Clement, (2011) claimed that $\mathrm{pH}$ of the electrolyte contributes significantly to the variation in hardness of coatings. In the experiment to deposit Cobalt Copper $(\mathrm{Co}-\mathrm{Cu})$ alloy thin films on amorphous substrate by electrodeposition, Liu et al., (2005) observed that a remarkably coarse surface at $\mathrm{pH} 2.2$ gradually smoothed into much more refined structure at $\mathrm{pH} 5.05 . \mathrm{pH}$ also impacts on conductivity of electrolyte (Nia et al., 2019).

The Faradic efficiency (FE), added mass and deposition rate increased with increasing electrolyte $\mathrm{pH}$, the $\mathrm{FE}$, gained mass and deposition rate were the lowest at $\mathrm{pH} 2.0$ but an increment of $\mathrm{pH}$ to 2.5 resulted in significant mass gain during a study of electrodeposition of Rhenium Iridium Nickel (Re-Ir-Ni) coatings(Wu et al., 2014). In the work of Go'mez et al., (2003), different stages of electroplating of Copper Molybdenum (CoMo) was reported to be $\mathrm{pH}$ dependent. Selection of $\mathrm{pH}$ below 5 helps to reduce internal stress level of deposits, lower $\mathrm{pH}$ can be used to manage deposited material internal stress (Güler, 2016).

\section{Throwing Power}

Measure of an electrolyte's ability to deposit a uniformly on an irregular shaped cathode is referred to as the throwing power. Throwing power is impacted by current density, electrolytic conductance and agitation of the electrolyte (Lou \& Huang, 2006). Higher throwing power is generally desirable in electrodeposition (Gamburga et al., 2002).

\section{ELECTRICAL PARAMETERS}

Electroplating parameter that revolves around electric current in the electrolyte were reviewed in the following sections. Key electrical parameter reviewed include; current, current density, current distribution and current efficiency.

\section{Electric Current}

Flow of electric current is vital in electrodeposition, deposition takes place in an electrolytic cell when flow of electric current is established. Direct current plating does not produce a uniform deposition thickness when plating objects with corners, the outside corners end up with a thicker deposition compared with recessed corners (Lou \& Huang, 2006). According to Chandrasekar and Pushpavanam, (2008), pulse current (PC) produces invariably fine-grained structures so that physical, chemical and mechanical properties are changed advantageously for many metals and alloys. It can equally affect the electro crystallization mechanism and control the physical and mechanical properties of the electrodeposit metal. The greater power consumption in PC can reduce bills for heating electrolytes but may cause overheating, particularly at low duty cycles. PC can influence the structure and composition of an alloy. Uniform composition can be obtained at high frequency pulses.

Periodic pulse reversed current waveform produces better uniformity, reduced porosity, improved hardness and decreased grain size of the deposited metal compared with direct current plating, it also allows precise control of the deposited material composition, crystallographic structure, texture and grain size (Trzaska \& Trzaska, 2008).

\section{Current Density}

Current density is the ampere per unit area of the electrode (Lou \& Huang, 2006) and it is inversely proportional to deposition time (Tuaweri et al., 2013) and it determines the uniform coating of the final deposit(Kumar et al., 2015). The higher the current density the higher the deposition rate up to a practical limit (Trzaska \& Trzaska, 2008). A cathode current density of $50 \mathrm{~mA} / \mathrm{cm}^{2}$ was considered optimum by Prasad et al (2000). An increase in current density up to $75 \mathrm{~mA} / \mathrm{cm}^{2}$ results in a decrease in the average grain size and texture coefficient of nickel 
coatings (Rashidi \& Amadeh, 2010), this was corroborated by (Celis et al., 2017) highlighting the dependency of grain size on current density and bath composition. Similarly, increase in the current density above $150 \mathrm{~mA} / \mathrm{cm}^{2}$ results in visible surface cracks in the coatings. The grain size and surface morphology of the coatings are also affected by change in current density (Oniku et al., 2015).

\section{Current Efficiency}

Current efficiency is the percentage of electric current flowing in an electroplating bath that achieves the desired deposition results (Lou \& Huang, 2006). It is expressed mathematically as; current efficiency $=100 \times{ }^{w_{\text {Act }}} / w_{\text {Theo }}$

where $w_{\text {Act }}$ is actual weight of the deposited or dissolved material and $w_{\text {Theo }}$ is the theoretical value of the deposited weight calculated according to equation (5). Changes in current efficiency of the bath appears to be insignificant over a range of current densities between 2.5-4.5 A/dm2 after which current efficiency drops significantly (Tuaweri et al., 2013).

\section{Current Distribution}

Current distribution is a complex phenomenon in electroplating, it is desirable to achieve a uniform current distribution in the electrolyte but this is usually concentrated around the edges of the electrodes and less around the middle (Tan \& Lim, 2003). Uniform current distribution could be achieved by varying parameters such as agitation, bath conductance and electrolyte concentration individually as combining the parameter does not produce the expected cumulative effect (Tan \& Lim, 2003).

\section{Electrolytic Conductance}

This is measurement of the ability of an electrolyte to conduct electricity and it is heavily dependent on the mobility of individual ions, viscosity and chemical composition of the electrolyte (Lou \& Huang, 2006). Temperature increases conductivity of electrolyte (Kumar et al., 2015). An electrodeposition simulation experiment performed with different electrolyte conductivities showed a decreasing thickness trend with decreasing electrolyte electrical conductivities (Mahapatro \& Suggu, 2018).

\section{PHYSICAL PARAMETERS}

These are the third category of parameters affecting quality of electrodeposition. They include temperature, time, agitation, etc. these and others are described next.

\section{Temperature of Electrolyte}

Bograchev \& Davydov, 2019 observed that the presence of temperature gradient enhances the uniformity of deposition as deposition happens at slower rates at lower temperatures. In effect, temperature affects conductivity of the solution. Increasing electrolyte temperature up to about $50^{\circ} \mathrm{C}$ results in corresponding increase in cathode current efficiency (Tuaweri et al., 2013) but temperature of $45^{\circ} \mathrm{C}$ produces best result (Prasad et al., 2000). Barbato et al., (2008) opined that plating at a temperature of $50^{\circ} \mathrm{C}$ produces deposit with a better hardness and finer grain size.

Electrolyte $\mathrm{pH}$ and temperature changes seem to have some effect on the morphology and preferred orientation of the electrodeposits (Tuaweri et al., 2013). Esmaret al., (2020) noted that, high electrodeposition temperature in the vicinity of $45^{\circ} \mathrm{C}$ could produce smoother morphology and $\mathrm{Ni}$ grain refinement with attendant increase in coating hardness. Raising temperature encourages formation of coatings with coarse and porous grains (Kumar et al., 2015; Ziti et al., 2012).

\section{Deposition Time}

For a specific deposit thickness, deposition time is inversely proportional to current density (Tuaweri et al., 2013) and it determines the plating thickness (Kumar et al., 2015). Time has a direct effect on deposition thickness (Sadiku-Agboola et al., 2011). Cvetković et al, (2020) conducted electrodeposition of aluminium onto glassy carbon and aluminium substrates and found that the shape and size of $\mathrm{Al}$ grains deposited depended on the time of deposition and varied in size from nanometers to micrometers and in shape from regular crystal forms to needlelike and flake-like structures.

Study of optimization of process parameter for electrodeposition of Nickel Chromium (Ni-Cr) for coating variation shows that plating time have more effect on thickness variations(Khedekar et al., 2016). Deposition time is directly proportional to the amount of metal coatings (Aygar \& Üstünışık, 2009; Wahab et al., 2013).

\section{Agitation /Stirring of Electrolyte}

Tuaweri et al. (2013) submitted that electrolyte agitation is slightly detrimental to the current efficiency after observing that bath agitation beyond $100 \mathrm{rpm}$ reduced the current efficiency. Agitation is important for producing smooth coating and eliminating pits in coatings (Kumar et al., 2015). Cathodic polarization studies showed that electrolyte agitation had significant effect on limiting current density and hence mass transport of the bath (Tuaweri et al., 2013). Pits formation is eliminated by bath agitation and helps produce smooth coatings (Kumar et al., 2015). Also, current distribution uniformity could be improved by optimal agitation of the electrolyte (Tan \& Lim, 2003).

Agitation of electrolyte helps to replenish metal salt or its ions around the cathode, thins out the diffusion layer, minimizes gas bubbles capable of promoting pits formation and increases operating current density (Paunovic \& Schlesinger, 1998).

\section{Electrode Porosity}

One of the main contributors for the high anode usage is anode porosity (Begum et al., 2013).

\section{Cathode Preparation}

In order to achieve best electroplating results, workpieces are subjected to pretreatments such as cleaning, modification and rinsing. While cleaning deals with removal of surface contaminants which can be achieved using mechanical or chemical means such as degreasing, alkaline cleaning and acid pickling, (Lou \& Huang, 2006) rinsing is done to remove dragouts.

\section{CONCLUSION}

The subject of electroplating has been reviewed with a focus on operational parameters, their impacts and how they affect quality electrodeposition. It was observed that impact of each of the reviewed parameter is highly dependent on other parameters 
interacting together during a given electrodeposition process. Cathode preparation is basic for electroplating, how well it is carried out has a direct effect on the final results. Electroplating is a very vast research field and these parameters are constantly being fine-tuned of to obtain a suitable plating environment for achieving desired result. Recommended optimum conditions varied being within limited scopes of discrete research endeavors. It is recognized that the field of electroplating will keep evolving with innovations for better product standard and optimum process design.

\section{ACKNOWLEDGEMENT}

The authors wish to thank Dr. Akinluwade K.J and Engr. Olabode O. for their invaluable contributions.

\section{REFERENCES}

Agasti, A., Rai, D., Mallick, S., \& Bhargava, P. (2014, December). Study of Optimization of $\mathrm{Zn}$ Salt Concentration in co-Electrodeposited Cu2ZnSnS4 (CZTS) Thin Films. 2014 IEEE International Conference on Power Electronics, Drives and Energy Systems.

Andre A. P., \& Maximiliano L.M. (2006). Electrodeposition. Encyclopedia of Chemical Processing, 821-832.

ASTMB374-06. (2019). Standard Terminology Relating to Electroplating. ASTM International, West Conshohocken, PA, 2019, www.astm.org.

Aygar, A. M., \& Üstünış1k, M. (2009, May). Investigation on the Factors that Affect the Amount of Metal Coated in an Electroplating Process. Retrieved February 8, 2020, from https://core.ac.uk/download/pdf/11725439.pdf

Barbato, S. R., Ponce, J. F., Jara, M. L., Cuevas, J. S., \& Egana, R. A. (2008). Study of the Effect of Temperature on the Hardness, Grain Size, and Yield in Electrodeposition of Chromium on 1045 Steel. Journal Of The Chilean Chemical Society, 53(1), 1429-1432.

Begum, S. S., Tarlochan, F., \& Sambasivam, K. (2013). Analyzing the Influence of Process Parameters on Anode Usage in Electroplating Process. Asian Journal of Applied Sciences, 6(1), 16-28.

Bhat, R. S., \& Hegde, A. C. (2012). Electrodeposition of Cyclic Multilayer Zn-Co Films Using Square Current Pulses and Investigations on Their Corrosion Behaviors. Journal of minerals and materials characterization and engineering, 11(9), 896-903.

Bograchev, D. A., \& Davydov, A. D. (2019). Effect of Applied Temperature Gradient on Instability of Template-Assisted Metal Electrodeposition. Electrochimica Acta- Elsevier, 10491054.

Celis, J. P., De Bonte, M., \& Roos, J. (2017). Electroplating Technology. The International Journal of Surface Engineering and Coatings, 89-93.
Chandrasekar, M. S., \& Pushpavanam, M. (2008). Pulse and Pulse Reverse Plating -Conceptual, Advantages and Applications. Electrochimica Acta, 53(8), 3313-3322.

Cvetković, V. S., Vukićević, N. M., Jovićević, N., Stevanović, J. S., \& Jovićević, J. N. (2020). Aluminium Electrodeposition Under Novel Conditions from AlCl3-Urea Deep Eutectic Solvent at Room Temperature. Transactions of Nonferrous Metals Society of China, 30(3), 823-834.

Esmar, B., Leli, K., Assita, W. A., Widyaningrum, I., Iwan, S., \& Prayitno, T. B. (2020). Effect of Temperature on Electrodeposited Nickel Nitride Composite Coatings. The 4th International Conference on Applied Physics and Materials Application.

Gamburga, Y., Groshevab, M., Biallozorc, S., \& Hassc, M. (2002). The electrochemical deposition of nickel from electrolytes containing malonic acid. Surface and Coatings Technology, 150(2002), 95-100.

Garcia J.C., \& Burleigh T.D. (2013). The Beginnings of Gold Electroplating. , 22(2), p.36. Electrochemical Society Interface, 22(2), 36.

Go'mez, E., Pellicer, E., \& Valle's, E. (2003). Influence of the bath composition and the $\mathrm{pH}$ on the induced cobalt/molybdenum electrodeposition. Journal of Electroanalytical Chemistry, 556(2003), 137-145.

Güler, E. S. (2016). Effects of Electroplating Characteristics on the Coating Properties. In A. M. Mohamed, \& T. D. Golden, Electrodeposition of Composite Materials (pp. 27-37). INTECH. doi:DOI: 10.5772/61745

Heong, C. Y., Haseeb, A. S., Yingxin, G., \& Fang, L. S. (2012). Effects of Sn Concentration and Current Density on Sn-Bi Electrodeposition in Additive Free Plating Bath. 4th Asia Symposium on Quality Electronic Design, 286-290.

Khedekar, D., Gosavi, V., Gogte, C., \& Brahmankar, P. (2016, December). Optimization of Process Parameters of Nickel Chromium Electroplating for Thickness Variation using Genetic Algorithm. International Conference on Communication and Signal Processing 2016, 41-47.

Kumar, A., \& Clement, S. (2011). Optimum Selection and Ranking of Electroplating System Process Parameters: TaguchiMADM Approach. International Journal of Applied Decision Science, 4(4), 341-361.

Kumar, S., Pande, S., \& Verma, P. (2015). Factor Effecting Electro-Deposition Process. International Journal of Current Engineering and Technology Vol.5, No.2, 700-703.

Liu, Q., Min, J. H., Cho, J. U., \& Kim, Y. K. (2005). The pH Dependence of $\mathrm{Co}-\mathrm{Cu}$ Alloy Thin Films Fabricated on Amorphous Substrate by DC Electrodeposition. IEEE Transactions on Magnetics, 41(2), 930-932. 
Lou, H. H., \& Huang, Y. (2006). Electroplating. Encyclopedia of Chemical Processing, 839-848.

Mahapatro, A., \& Suggu, S. K. (2018). Modeling and Simulation of Electrodeposition: Effect of Electrolyte Current Density and Conductivity on Electroplating Thickness. Advanced Material Science, 3(2), 1-9.

Mokabber, T., Rastegari, S., \& Razavizadeh, H. (2013). Effect of Electroplating Parameters on Properties of $\mathrm{Zn}-\mathrm{Nano}-\mathrm{TiO} 2$ Composite Coatings. Surface Engineering, 29(1), 41-45.

Nia, P. M., Jenatabadi, H. S., Woi, P. M., \& Abouzari-Lotf, E. (2019). The Optimization of Effective Parameters for Electrodeposition of Reduced Graphene Oxide through Taguchi Method to Evaluate the Charge Transfer. Measurement, 683690.

Oniku, O. D., Qi, B., \& Arnold, D. P. (2015). Effect of Current Density on Electroplated CoPt Thick Films. 18th International Conference on Solid-State Sensors, Actuators and Microsystems (TRANSDUCERS), 596-601.

Paunovic, M., \& Schlesinger, M. (1998). Fundamentals of electrochemical deposition. New York.

Prasad, S., Marinho, F., \& Santana, F. (2000). Control and Optimization of Baths for Electrodeposition of Co-Mo-B Amorphous Alloys. Brazilian Journal of Chemical Engineering, 17, 4-7.

Rashidi, A. M., \& Amadeh, A. (2010). Effect of Electroplating Parameters on Microstructure of Nanocrystalline Nickel Coatings. Journal of Material Science Technology, 26(1), 8286.

Sadiku-Agboola, O., Sadiku, E. R., Ojo, O. I., Akanji, O. L., \& Biotidara, O. F. (2011). Influence of Operation Parameters on Metal Deposition in Bright Nickel-Plating Process. Portugaliae Electrochimica Acta,, 29(2), 91-100.

Si, C., Fei, Q., Tong, A., \& Pei, C. (2016, May). Effect of Electroplating Parameter on the TSV - $\mathrm{Cu}$ Protrusion during Annealing and Thermal Cycling. IEEE 66th Electronic Components and Technology Conference (ECTC), 1599-1604.

Sui, X., Huang, Y., Han, T., \& Zeng, X. (2017, April). Analysis on the Influential Factors of $\mathrm{Cu} 2+$ Electro-deposition. AIP Conference Proceedings.1829, p. 020042. AIP Publishing LLC.

Tan, Y. J., \& Lim, K. Y. (2003). Understanding and Improving the Uniformity of Electrodeposition. Journal of Surface and Coatings Technology, 167(2-3), 255-262.
Tang, J., Mao, S., Wang, H., Liu, R., \& Ding, G. (2010, January). Effect of Additives on Mechanical Properties of Electroplating Nickel.IEEE 5th International Conference on Nano/Micro Engineered and Molecular Systems, 450-453.

Thomson T. (1813). On the Daltonian theory of definite proportions in chemical combinations. Annals of philosophy,, 2, 32.

Trzaska, M., \& Trzaska, Z. W. (2008). Control of Nano- and Micro-crystalline Copper Electrodeposits. American Control Conference, 2196-2201.

Tuaweri, T. J., Adigio, E. M., \& Jombo, P. P. (2013). A Study of Process Parameters for Zinc Electrodeposition from a Sulphate Bath. International Journal of Engineering Science Invention, 2(8), 17-24.

Wahab, H. A., Noordin, M. Y., Izman, S., \& Kurniawan, D. (2013). Quantitative Analysis of Electroplated Nickel Coating on Hard Metal. The Scientific World Journal, 1-6.

Walsh, F. C., Wang, S., \& Zhou, N. (2020). The Electrodeposition of Composite Coatings: Diversity, Applications and Challenges. Current Opinion in Electrochemistry, 20, 8-19.

Wei Han. (2012, March 22). Electroplating/ Electrodeposition. $A B C$ of Electrochemistry. Ohio, USA: Ohio University.

Wu, W., Eliaz, N., \& Gileadi, E. (2014). The Effects of pH and Temperature on Electrodeposition of Re-Ir-Ni Coatings from Aqueous Solutions. Journal of The Electrochemical Society, 162(1), D20-D26.

Yin, T., Wu, R., Leng, Z., Du, G., Guo, X., Zhang, M., \& Zhang, J. (2013). The Process of Electroplating with $\mathrm{Cu}$ on the Surface of Mg-Li Alloy. Surface and Coatings Technology, 225, 119125 .

Yu, J. K., Sun, H., Zhao, L. L., Wang, Y. H., Yu, M. Q., Luo, H. L., \& Matsugi, K. (2017). Effects of Electrolyte Concentration and Current Density on the Properties of Electrodeposited NiFeW Alloy Coatings. Bulletin of Materials Science, 40(3), 577-582.

Zangari, G. (2018). Fundamentals of Electrodeposition. Elsevier inc.

Ziti, Z., Fakurol, R., \& Yusairie, M. (2012). The influence of Deposition Temperature on the Electrodeposition of NiO Films on ITO-Glass Substrate. IEEE Symposium on Humanities, Science and Engineering Research, 531-535 International license viewed via https://creativecommons.org/licenses/by/4.0/ which permits unrestricted use, distribution, and reproduction in any medium, provided the original work is cited appropriately. 